\title{
Effects of natural and synthetic antioxidants on changes in refined, bleached, and deodorized palm olein during deep-fat frying of potato chips
}

\begin{abstract}
The effects of antioxidants on the changes in quality characteristics of refined, bleached, and deodorized (RBD) palm olein during deep-fat frying (at $180^{\circ} \mathrm{C}$ ) of potato chips for $3.5 \mathrm{~h} / \mathrm{d}$ for seven consecutive days in five systems were compared in this study. The systems were RBD palm olein without antioxidant (control), with 200 ppm butylated hydroxytoluene (BHT), 200 ppm butylated hydroxyanisole (BHA), 200 ppm oleoresin rosemary, and 200 ppm sage extract. Fried oil samples were analyzed for peroxide value (PV), thiobarbituric acid (TBA) value, iodine value (IV), free fatty acid (FFA) content, polymer content, viscosity, E1\% $1 \mathrm{~cm}$ at 232 and $268 \mathrm{~nm}$, color, fatty acid composition, and C18:2/C16:0 ratio. Sensory quality of the potato chips fried in these systems prior to storage was also evaluated. The storage stability of fried potato chips for $14 \mathrm{wk}$ at ambient temperature was also determined by means of the TBA values and sensory evaluation for rancid odor. Generally, in the oil, oleoresin rosemary gave the lowest rate of increase of TBA value, polymer content, viscosity, E1\% $1 \mathrm{~cm}$ at 232 and $268 \mathrm{~nm}$ compared to control and three other antioxidants. The order of effectiveness $(\mathrm{P}<0.05)$ in inhibiting oil oxidation in RBD palm olein was oleoresin rosemary $>$ BHA > sage extract > BHT > control. Prior to storage, the sensory evaluation of fried potato chips for each system showed that there was no significant $(\mathrm{P}>0.05)$ difference in terms of flavor, odor, texture, and overall acceptability. The same order of effectiveness $(\mathrm{P}<0.05)$ of antioxidants was observed for storage stability study of fried potato chips by TBA values. However, there was no significant $(\mathrm{P}>0.05)$ difference in sensory evaluation for rancid odor during storage periods.
\end{abstract}

Keyword: Antioxidant; BHA; BHT; Deep fat frying; Quality characteristics; RBD palm olein; Rosemary; Sage 